\title{
Câmbio real, poupança doméstica e poupança externa: análise teórica e evidências empíricas
}

Marcos Rocha Professor da PUC-SP

Paulo Gala Professor da EESP-FGV

\begin{abstract}
Palauras-chave
nível do câmbio real, poupança doméstica, poupança externa, desenvolvimento econômico, deslocamento de poupança.
\end{abstract}

\section{Classificação JEL F3, F4,} $\mathrm{O} 2$.

\section{Key words}

real exchange rate, savings, investment and economic development, savings displacement.

JEL Classification F3, F4, O2.

\section{Resumo}

Este trabalho tem como principal objetivo investigar as relações entre nível da taxa de câmbio real, poupança externa e poupança doméstica em países emergentes. Dentro do modelo aqui explorado, casos de sobrevalorização excessiva do câmbio real levam a redução de margens de lucro nos setores de produção de bens comercializáveis, resultando numa queda importante no nível de poupança agregada doméstica. A análise econométrica do trabalho indica que a desvalorização relativa da taxa de câmbio parece ter impactos relevantes nos níveis de poupança doméstica de países em desenvolvimento. Os resultados das estimações, em todas as especificações, apontam para uma robusta e significativa relação positiva entre o índice de desvalorização relativa da taxa de câmbio real calculada e a poupança doméstica/PIB.

\section{Abstract}

This paper provides theoretical and empirical elements to analyze the relation between real exchange rates and domestic savings. We show from a theoretical perspective how a competitive exchange rate may stimulate domestic savings by avoiding consumption booms based on currency overvaluation and by increasing profits in the tradable sector. Our baseline model shows from a short run perspective how a competitive exchange rate may stimulate investment, exports, profits and thus domestic savings. We also present econometric evidence based on a panel with developing countries which shows a robust connection between real exchange rates and domestic savings as a share of GDP. 


\section{1_Introdução}

O principal objetivo deste trabalho é investigar as relações entre nível da taxa de câmbio real, poupança externa e poupança doméstica em países emergentes. O interesse sobre os efeitos do nível da taxa de câmbio real em dinâmicas de crescimento de longo prazo tem crescido nos últimos anos (Frenkel e Taylor, 2006; Bresser-Pereira, 2006; Eichengreen, 2008; Rodrik, 2008 e Williamson, 2008). Como ressaltam alguns autores, é possível que os efeitos da política macroeconômica de câmbio competitivo e superávit comercial atuem de maneira benéfica sobre a poupança doméstica, contribuindo, assim, para o crescimento econômico. Tal associação também pode advir, por exemplo, da simples observação de que diversos países asiáticos têm mostrado simultaneamente taxas de câmbio competitivas e altas taxas de poupança. A China é o exemplo mais proeminente, seguida por Coreia, Malásia, Tailândia, entre outras. Estratégias de manutenção de competitividade do câmbio real para promover o crescimento das exportações e do produto já têm suporte empírico, mas os canais teóricos pelos quais o câmbio atua sobre o crescimento ainda são pouco conhecidos.
No plano de política econômica, o uso excessivo de poupança externa em países emergentes tem recebido inúmeras críticas. Essa visão ressalta, em geral, os efeitos potencialmente negativos dos fluxos de poupança externa sobre o endividamento e sobre a poupança doméstica de países emergentes, que configurariam obstáculos importantes a estratégias de desenvolvimento de longo prazo (Bresser-Pereira, 2006; Bresser e Nakano, 2003). Muitos trabalhos empíricos mostram os efeitos negativos da utilização de poupança externa sobre a doméstica, no que ficou conhecido na literatura como "savings displacement" (Edwards, 1995; Reinhart e Talvi, 1998). Os canais pelos quais a poupança externa afeta negativamente a poupança doméstica são debatidos por diversas pesquisas da linha pós-keynesiana, como Bresser Pereira (2006) e o seminal artigo de Badhuri e Marglin (1990).

Num trabalho recente, Montiel e Sérven (2008) notam que há crescimento na profissão de adeptos da ideia de que o nível da taxa de câmbio real tem efeitos importantes sobre o crescimento porque afeta a acumulação de capital. A visão tradicional de que são os "desalinhamentos" (ou os desvios temporários 
da taxa de câmbio real do seu nível de equilíbrio) que acometem o crescimento por distorcerem um preço relativo crucial da economia perde força, e a percepção de que a depreciação do câmbio real por longos períodos é o que promove o crescimento de alguns países ganha destaque. Estimulados por esse debate, os autores avaliam a possível ligação entre a taxa de câmbio e a poupança doméstica. Seus resultados mostram, entretanto, que é muito pouco provável que o mecanismo pelo qual a taxa de câmbio atinge o crescimento seja seus efeitos sobre a poupança agregada.

Este trabalho pretende contribuir para o debate, em especial explorando a relação empírica do movimento de resposta da poupança doméstica a fluxo de capitais estrangeiros que não é consensual na literatura. Mais especificamente, este artigo mostra que, mesmo controlada pelo Produto Interno Bruto (PIB) como questionado em Montiel e Sérven (2008) -, a hipótese de deslocamento da poupança interna se mantém.

Assim, partindo de uma perspectiva teórica e empírica diversa da de Montiel e Sérven (2008), encontramos resultados empíricos contrários daqueles apresentados pelos autores. Além dessa breve introdução, o trabalho está dividi- do em três seções. A seção 2 apresenta perspectivas teóricas dos efeitos da depreciação cambial sobre níveis de renda, consumo, investimento agregado e poupanças interna e externa; além disso, avalia teoricamente a influência da poupança externa sobre a doméstica. A seção 3 apresenta a análise empírica, e a seção 4 traz algumas conclusões.

\section{Análise teórica}

Montiel e Sérven (2008) avaliam a possível ligação entre a taxa de câmbio real e o nível de poupança doméstica. Eles encontram, num primeiro momento, relação positiva entre a apreciação cambial e o nível de poupança em análises crosscountry. Seus resultados mostram, entretanto, que, apesar de algumas evidências preliminares favoráveis, é muito pouco provável que o mecanismo pelo qual a taxa de câmbio afete o crescimento seja seus efeitos sobre a poupança agregada. Montiel e Sérven (2008) argumentam que, na verdade, essa relação positiva entre câmbio e poupança pode esconder correlação entre outros determinantes, entre os quais o principal seria o nível de renda per capita, que tem impacto tanto sobre o nível de taxa de câmbio - mediante o efeito Balassa-Samuelson - $\mathrm{CO}^{-}$ 
mo nas taxas de poupança doméstica. Os autores encontraram nos seus testes empíricos que, controlando pelo efeito da renda per capita, há mesmo relação contrafatual negativa entre taxas de poupança e desvalorização do câmbio real, embora seja de pequena magnitude e não significante estatisticamente.

Diante disso, Montiel e Sérven (2008) desenvolvem um arcabouço teórico para entender como um canal de transmissão das taxas de câmbio para o crescimento poderia acontecer no contexto de um modelo convencional de economia aberta. Mais especificamente, analisam o efeito de uma depreciação da taxa de câmbio de equilíbrio sobre a poupança num modelo de agente representativo com otimização intertemporal. Os autores introduzem a taxa de câmbio como uma variável de "meta de política". A principal conclusão a que os autores chegam com base nessa estratégia teórica é a de que a poupança doméstica aumenta em resposta à depreciação da taxa de câmbio real apenas se a depreciação gerar aumento transitório na renda real.

Neste trabalho temos uma proposta diferente. Para abordar teoricamente os efeitos do nível do câmbio real no crescimento pela via da acumulação de capital, apresentamos um modelo de determinação da renda de curto prazo que tem sua dinâmica de poupanças fundamentalmente determinada pelo nível da taxa de câmbio real. A análise se divide em três etapas:

i. impactos do câmbio real nos salários e nos lucros;

ii. impactos dos salários e dos lucros no nível de renda;

iii. impactos do nível do câmbio real nas poupanças doméstica e externa.

\subsection{Câmbio real, salários e lucros}

Começamos com uma análise dos efeitos da apreciação cambial nas margens de lucro agregadas e no salário real (BresserPereira, 2006). Embora modelos mais complexos possam derivar a análise de deslocamento de poupança, para os fins de nosso exercício empírico, um modelo kaleckiano simples é proposto para estruturar os resultados que depois serão empiricamente ilustrados.

A análise parte de uma divisão hipotética da economia em três setores:
i. tradables puros;
ii. non-tradables puros; e
iii. non-tradables com insumos tradables,

e de uma regra de formação de preços em ambiente de concorrência imperfeita: 
$\mathrm{p}_{\mathrm{i}}=\frac{\left(1+\mathrm{m}_{\mathrm{i}}\right) \mathrm{w}}{\mathrm{b}}$

onde $p$ é o nível de preços do setor $i, m$ o nível de mark-up do setor $i, b$ a produtividade do trabalho, e $w$ o salário nominal.

Para o setor de non-tradables puro, o nível de preços dependerá do mark-up, do salário nominal e da produtividade, todos constantes no curto prazo. Rearranjando-se os termos, o mark-up, por sua vez, dependerá do salário nominal, da produtividade e do nível de preços de non-tradables:

$\mathrm{p}_{\mathrm{nt}}=\frac{\left(1+\mathrm{m}_{\mathrm{nt}}\right) \mathrm{w}}{\mathrm{b}}$

$\mathrm{m}_{\mathrm{nt}}=\frac{\mathrm{bp} \mathrm{p}_{\mathrm{nt}}}{\mathrm{w}}-1$

O mesmo raciocínio pode ser aplicado para o setor de tradables puro, com uma diferença. Para uma economia aberta e relativamente pequena (price taker), os preços de tradables são endógenos e determinados pelo câmbio nominal $(e) \mathrm{e}$ preços em dólares $p^{*}$ :

$$
\begin{aligned}
& \mathrm{p}_{\mathrm{t}}=\frac{\left(1+\mathrm{m}_{\mathrm{t}}\right) \mathrm{w}}{\mathrm{b}} \\
& \mathrm{p}_{\mathrm{t}}=\mathrm{ep}^{*} \\
& \mathrm{~m}_{\mathrm{t}}=\frac{\mathrm{bep}^{*}}{\mathrm{w}}-1
\end{aligned}
$$

Uma apreciação cambial reduz o preço de venda dos tradables, e tudo o mais constante (ou seja, salários nominais, preços externos e produtividade) reduz a margem de lucro do setor de tradables. No entanto, a apreciação cambial pode aumentar os lucros do setor nontradables, que opera com insumos importados. No caso do setor de tradables que opera com insumos tradables, uma apreciação cambial sempre reduzirá o markup, uma vez que a queda no preço de venda tende a ser maior do que a queda de um componente parcial do custo. $\mathrm{O}$ argumento de que o câmbio apreciado é favorável ao investimento agregado por baratear o preço de máquinas e equipamentos pode ser entendido aqui como uma situação em que o preço reduzido de insumo aumenta a margem de lucro para um setor non-tradable. Em termos agregados, o que ocorreria com o nível de mark-up? O mark-up agregado pode ser entendido como a média ponderada pelo tamanho de cada setor $(j, k, l)$. Assim:

$\mathrm{jm}_{\mathrm{t}}+\mathrm{km}_{\mathrm{nt}}+\mathrm{lm}_{\mathrm{it}}=\mathrm{m}$

Uma apreciação cambial reduz o mark-up do setor de tradables, mantém inalterado o mark-up do setor de non-tradables e aumenta o mark-up do setor non- 
tradables com insumos tradables. O efeito final sobre o mark-up geral do sistema dependerá do tamanho relativo de cada setor. Se o setor de tradables for maior do que o setor de non-tradables com insumos tradables $(x>z)$, necessariamente uma apreciação cambial reduzirá o mark-up do sistema. Quanto maior o componente non-tradable de custo de produção de tradables, maior será o efeito nos mark-ups.

Resta ver como ficam as outras variáveis do sistema como decorrência da apreciação (depreciação) cambial. $\mathrm{O}$ nível geral de preços deve cair (subir), já que é um composto de preço de tradables e non-tradables:

$\mathrm{p}=\alpha e \mathrm{p}^{*}+(1-\alpha) \mathrm{p}_{\mathrm{nt}}$

O salário real deve aumentar (cair), pois é uma relação entre salário nominal e nível de preços:

$$
\frac{\mathrm{w}}{\mathrm{p}}=\frac{\mathrm{w}}{\alpha e \mathrm{p}^{*}+(1-\alpha) \mathrm{p}_{\mathrm{nt}}}
$$

O câmbio real deve se apreciar (depreciar), na medida em que o câmbio nominal cai (sobe) mais do que o aumento do nível geral de preços que depende, em parte, dos preços de non-tradables.

$\theta=\frac{\mathrm{ep}^{*}}{\mathrm{p}}$
E, por fim, se assumirmos que o setor de tradables é maior do que o de nontradables com insumos importados, o mark-up agregado do sistema deve cair. Ou seja, para dados níveis de produtividade e salário nominal, uma apreciação cambial resulta numa redução nas margens de lucro do sistema e aumentos do salário real.

\subsection{Câmbio real e nível de renda}

Vejamos, agora, como a determinação da renda, do investimento e da poupança é afetada por essa queda de mark-ups e lucros no curto prazo. Seguindo Bhaduri e Marglin (1990), partimos da definição da poupança agregada $S$ dependendo de uma parcela fixa $s$ do lucro dos capitalistas. Os trabalhadores consomem o total de sua renda e, portanto, não poupam. Temos, assim:

$\mathrm{S}=\mathrm{sR}=\mathrm{s}\left(\frac{\mathrm{R}}{\mathrm{Y}}\right)\left(\frac{\mathrm{Y}}{\mathrm{Y}^{*}}\right) \mathrm{Y}^{*}$

onde $R$ é a renda dos capitalistas, e $Y^{*}$, o produto potencial. Definindo-se $h=R / Y$ como a porcentagem de renda dos capitalistas em relação à renda total, $z=Y / Y^{*}$ como o nível de utilização de capacidade instalada, e o produto potencial como $Y^{*}=1$, chegamos em: 


$$
\begin{aligned}
& S=\operatorname{shz} \\
& 1>h>0 \\
& 1>z>0
\end{aligned}
$$

Definindo-se $W / Y$ como a participação dos trabalhadores na renda, $N$ como trabalhadores empregados $\mathrm{e}$ $1 / b=N / Y$, temos que:

$$
\frac{\mathrm{W}}{\mathrm{Y}}=\frac{\mathrm{wN}}{\mathrm{pY}}=\frac{1}{\mathrm{~b}^{*}} \cdot \frac{\mathrm{W}}{\mathrm{P}}=\frac{1}{1}+\mathrm{m}
$$

A participação dos capitalistas na renda, $h=R / Y$ será:

$$
\begin{aligned}
\mathrm{h} & =\frac{\mathrm{R}}{\mathrm{Y}}=\frac{\mathrm{pY}-\mathrm{wN}}{\mathrm{pY}}= \\
& =1-\frac{\mathrm{W}}{\mathrm{Y}}=\frac{\mathrm{m}}{1}+\mathrm{m}
\end{aligned}
$$

Levando-se em consideração a hipótese de que os trabalhadores consomem toda sua renda, aumentos dos salários reais significarão redução da poupança interna e aumento de consumo. Como consequência, a demanda agregada poderá cair ou aumentar, dependendo dos efeitos da queda das margens de lucro na função investimento.

A função investimento do modelo depende positivamente da margem de lucro $h$ e do nível de utilização da capacidade instalada $\%$

$$
\mathrm{I}=\mathrm{I}(\mathrm{h}, \mathrm{z}), \mathrm{I}_{\mathrm{h}}>0, \mathrm{I}_{\mathrm{z}}>0
$$

Poupança e investimento se igualam no equilíbrio do mercado de bens em uma economia fechada (que define uma relação IS):

$\operatorname{sh} z=I(h, z)$

O nível de utilização da capacidade instalada em relação a margens de lucro dependerá da seguinte derivada:

$$
\begin{aligned}
& \frac{\partial z}{\partial h}=\frac{I_{h}-s z}{s h-I_{z}} \\
& I_{h}=\frac{\partial I}{\partial h}>0
\end{aligned}
$$

A partir da condição de que o equilíbrio no mercado de bens se dá por variações do nível de poupança e não de investimento $\left(s h-I_{z}>0\right)$, e como sh é sempre positivo, a utilização da capacidade instalada aumentará ou diminuirá, dependendo da diferença $\left(I_{b}-s ₹\right)$.

Se o investimento for pouco elástico a variações nas margens de lucro, quedas de salário real terão efeitos recessivos, visto que a queda do consumo não será compensada por um aumento de investimento dos empresários $\left(I_{b}<s ₹\right)$. Essa é a clássica tese do subconsumo, em que redução de salário real diminui o consumo e a demanda agregada, e, nesse caso, o regime de acumulação nessa economia poderia ser caracte- 
rizado como "wage-led". Por outro lado, se os investimentos forem altamente sensíveis à margem de lucro, teremos, então, o efeito oposto. Redução do salário real aumentará os lucros, que, por sua vez, aumentarão a demanda agregada e a utilização de capacidade instalada. A economia será, nessa situação, descrita como em um regime que atua com "profit-led growth".

\section{3_Câmbio real, poupança externa e poupança doméstica}

Estendendo o modelo para uma economia aberta, seguimos Bhaduri e Marglin (1990) com funções para o volume de exportações $X_{e}$ e importações $X_{m}$, que dependem respectivamente do câmbio real $\theta$ e do nível de utilização de capacidade instalada $₹$, com a seguinte elasticidade:

$$
\begin{aligned}
& \left(\frac{d X_{e}}{d \theta}\right)\left(\frac{\theta}{X_{e}}\right)=\eta_{e} \\
& \left(\frac{d X_{m}}{d \theta}\right)\left(\frac{\theta}{X_{m}}\right)=-\eta_{m} \\
& \left(\frac{d X_{m}}{\partial z}\right)\left(\frac{z}{X_{m}}\right)=u
\end{aligned}
$$

No novo equilíbrio do mercado de bens, o total da poupança mais o gasto com importações $M$ deverão se igualar ao total do investimento mais o gasto em exportações $E$,
$\operatorname{shz}+\mathrm{M}=\mathrm{I}(\mathrm{h}, \mathrm{z})+\mathrm{E}$

A derivada parcial de utilização de capacidade instalada em relação à margem de lucro será muita próxima da situação de economia fechada (expressão 19):

$\frac{\partial z}{\partial h}=\left(I_{h}-s z\right)\left(g u+s h-I_{z}\right)$

onde $g$ representa a participação inicial de importações e exportações sobre o produto e $u$ é a elasticidade do volume de importações em relação à utilização da capacidade instalada. Novamente assumindo que $\left(g u+s h-I_{z}\right)>0$, chega-se a conclusões semelhantes às desenvolvidas inicialmente.

No modelo em economia aberta, para dados níveis de produtividade, uma desvalorização real do câmbio reduzirá o salário real e aumentará a margem de lucro dos empresários se o setor de bens transacionáveis for maior do que o setor de bens não transacionáveis que usa insumos importados (conforme (7)). Haverá aumento de investimento, exportações e nível de renda, contanto que as funções sejam suficientemente elásticas. No caso das exportações e das importações, o efeito total sobre a balança comercial e contas-correntes será positivo se valer a condição Marshall Lerner $\left(\eta_{\mathrm{e}}+\eta_{\mathrm{m}}>1\right)$. 
Segundo essa linha de raciocínio, a poupança externa financia o consumo, não o investimento. $\mathrm{O}$ aumento do consumo deve-se à taxa de câmbio impactar sobre os salários e os ordenados reais. Se a taxa de câmbio estiver sobrevalorizada, os salários e ordenados reais estarão artificialmente elevados, e, consequentemente, o consumo doméstico e as importações também estarão - dada a elevada propensão marginal a consumir -, o que faz com que a poupança interna se reduza. Portanto, uma estratégia de desenvolvimento com poupança externa, viabilizada por políticas que atraiam capitais internacionais, valoriza a taxa de câmbio, o que, via salários e ordenados reais artificialmente elevados, faz com que a poupança interna se reduza.
Em sua forma resumida, o modelo mostra que o equilíbrio macroeconômico pode ser expresso como:

$$
\begin{aligned}
\mathrm{y} & =\mathrm{C}+\mathrm{I}+\mathrm{E}-\mathrm{M}= \\
& =\mathrm{C}(\theta)+\mathrm{I}(\mathrm{h}(\theta), \mathrm{z})+\mathrm{E}(\theta)+\mathrm{M}(\theta, \mathrm{z})
\end{aligned}
$$

Em termos de equilíbrio de poupanças, teremos que:

$$
\mathrm{S}+\mathrm{M}-\mathrm{E}=\mathrm{I}
$$

Ou, como expresso em (22)

$\operatorname{sh}(\theta) z+M(\theta, z)-E(\theta)=I(h(\theta), z)$

A trajetória de poupanças interna e externa depende do câmbio, já que este afeta todas as variáveis acima elencadas. Com funções suficientemente elásticas, um câmbio real mais depreciado poderá aumentar o nível de renda via incremento de exportações, reduzir o nível de consumo, ampliar a poupança interna, reduzir a poupança externa e elevar o nível de investimento. Um câmbio real mais apreciado pode resultar numa trajetória de crescimento puxado por consumo com déficits em conta-corrente. Haveria aqui o caso da substituição da poupança interna pela externa, como destacado em Bresser-Pereira (2006). ${ }^{1}$

\section{3_Análise empírica}

O objetivo da presente seção é testar se a taxa de câmbio real tem efeitos sobre as poupanças interna e externa valendose da análise de um painel de 83 países de renda média - países low-middle income e bigh-middle income, segundo a classificação do Banco Mundial - para o período de 1980 a 2000. Os dados foram obtidos na Penn World Tables 6.2 de Heston, Summers e Atina (2006) e nas séries do World Development Indicators, do Banco Mundial.

\section{1_Nível do câmbio real}

Num primeiro passo, estimamos o índice de desalinhamento defendido por Rodrik (2008), com dados da World Penn Tables 6.2 para câmbio nominal (XRAT), paridade de poder de compra $(P P P)$ e o logaritmo da série de produto per capita $(\ln R G D P C H)$. O autor apresenta a construção de um índice de desalinhamento com base em uma equação de câmbio de longo-prazo PPP, corrigido o efeito Balassa-Samuelson.

De acordo com Rodrik, tal medida, que tem a vantagem de ser comparável entre os países ao longo do tempo, é calculada em três passos. Primeiro, utilizam-se as taxas de câmbio nominais e os fatores de conversão da paridade de poder de compra para calcular as taxas de câmbio real dos países $i$ no período $t$. A equação (14) mostra esse cálculo, com variáveis utilizadas em logaritmos: 


$$
\ln \mathrm{RER}_{\mathrm{it}}=\ln \left(\frac{\mathrm{XRAT}_{\mathrm{it}}}{\mathrm{PPP}_{\mathrm{it}}}\right)
$$

Uma taxa de câmbio real maior do que 1 significa que o valor da moeda é menor do que a indicada pela paridade do poder de compra. Entretanto, como na prática os bens não comercializáveis são mais baratos nos países mais pobres (de acordo com o efeito Balassa-Samuelson), faz-se necessário um ajuste. Dessa forma, no segundo passo, regredimos a taxa de câmbio real sobre o PIB per capita (InRGDPCH), conforme mostra (28) sendo $f_{\mathrm{t}}$ o efeito fixo para o período de tempo e $\mathrm{u}_{\mathrm{it}}$ o termo erro.

$\mathrm{RER}_{\mathrm{it}}=\alpha+\beta \ln \mathrm{RGDPCH}_{\mathrm{it}}+\mathrm{f}_{\mathrm{t}}+\mathrm{u}_{\mathrm{it}}$

Finalmente, o último passo é o cálculo do índice de desalinhamento, que, nesse caso, é medido como uma desvalorização real no tempo em relação ao seu valor de longo prazo (Depreciação Real). Esse índice é calculado de acordo com (29): a diferença entre a taxa de câmbio real atual, $\ln R E R_{i p}$ e a previsão da regressão em painel da taxa de câmbio ajustada pelo efeito Balassa-Samuelson, $\ln \overline{\mathrm{RER}}_{i f}$ :

$$
\begin{aligned}
\ln (\text { Depreciação Real })=\ln \mathrm{RER}_{\mathrm{it}}- \\
-\ln \overline{\mathrm{RER}}_{\mathrm{it}}
\end{aligned}
$$

Assim, a "Depreciação Real" é comparável entre países e no tempo.
Quando "Depreciação Real" excede a unidade, indica que a taxa de câmbio é tal que os bens produzidos domesticamente são mais baratos, em termos de dólares - a moeda é relativamente depreciada com relação a sua trajetória de longo prazo. Valores abaixo de 1 na escala da direita significam sobrevalorização do câmbio e acima de 1, subvalorização.

$\mathrm{Na}$ regressão com nossos dados, reportada na Tabela 1 , obtivemos um coeficiente estimado $\beta=-0,133$, o que sugere forte efeito Balassa-Samuelson: quando a renda aumenta em $10 \%$, a taxa de câmbio aprecia em torno de $1,3 \%$.

\subsection{Nível do câmbio real, poupança doméstica e poupança externa}

A fim de estimar a função de poupança doméstica, são utilizados os estimadores de métodos generalizados de momentos (Generalized Method of Moments - GMM) para painel dinâmico de Arellano e Bond (1991) e Blundell e Bond (2000). Esses estimadores lidam com efeitos temporais não observáveis por meio da inclusão de interceptos específicos ao período. Tratar desses efeitos não é simples. Por isso, o modelo é dinâmico e pode conter regressores endógenos, que são controlados pela instrumentação das suas diferenças. 
Tabela 1_Estimação da taxa de câmbio real de longo prazo PPP, corrigida pelo efeito Balassa-Samuelson

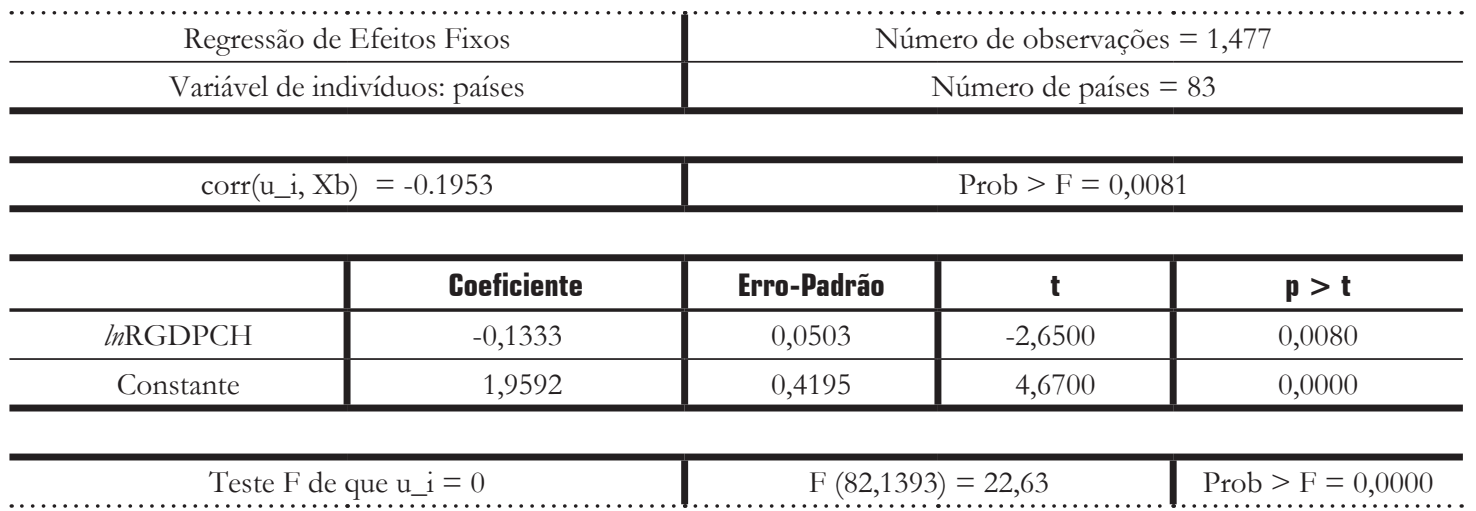

Fonte: Resultados da pesquisa.

Os instrumentos correspondentes às condições de momentos são valores defasados tanto em nível como em diferença das variáveis explicativas e dependentes. Uma vez que, tipicamente, as condições de momento sobre-identificam a regressão do modelo, o método do painel dinâmico permite teste de especificações através do teste de Sargan. Trabalhando sobre os estimadores de Arellano e Bover (1995), Blundell e Bond (2000) desenvolveram um estimador em sistema (System-GMM) que usa condições de momentos adicionais. Os estimadores de Arellano-Bond (1991) e Blundell e Bond (2000) foram considerados adequados para a análise deste trabalho, por permitirem uma especificação dinâmica (possibilitando a variável dependente defasada), e por instrumentalizarem adequadamente variáveis potencialmente endógenas. Para uma descrição detalhada dessas metodologias econométricas, ver Baltagi (2005). A equação estimada para a poupança doméstica é a seguinte:

$$
\begin{aligned}
& \left(\frac{\mathrm{S}}{\mathrm{Y}}\right)_{\mathrm{it}}=\alpha_{\mathrm{i}}+\left(\frac{\mathrm{S}}{\mathrm{Y}}\right)_{\mathrm{it}-1}+\left(\frac{\mathrm{CA}}{\mathrm{Y}}\right)_{\mathrm{it}}+ \\
& +(\ln \text { Depreciação Real })_{\text {it }}+ \\
& +\mathrm{DPIB}_{\mathrm{it}}+\mathrm{OPENK}_{\mathrm{it}}+\mathrm{IED}_{\mathrm{it}}+ \\
& +\mathrm{KG}_{\mathrm{it}}+\mathrm{I}_{\mathrm{it}}+\mathrm{PIB}_{\mathrm{it}}+\psi_{\mathrm{t}}+\varepsilon_{\mathrm{it}}
\end{aligned}
$$

onde:

$(S / Y)_{i t}$ é a poupança doméstica sobre o PIB do país $i$ no período $t$, construída valendo-se das séries do World Development Indicators;

$(S / Y)_{i+1}$ é $(S / Y)_{i t}$ defasada em um período; 
$(C A / Y)_{\text {it }}$ é a conta-corrente sobre o PIB medida em dólares do país $i$ no período $t$, construída com base nas séries do World Development Indicators;

( $\ln$ Depreciação Real) $)_{\text {it }}$ é o índice de desvalorização relativa do câmbio real construída como explicado anteriormente;

$D P I B_{i t}$ é a taxa de crescimento do produto per capita do país $i$ no período $t$, construída tendo em vista as séries do World Development Indicators;

OPENK ${ }_{i t}$ é uma série da World Penn Tables 6.2, que mede o grau de abertura comercial do país como (exportações + importações)/PIB;

$I E D_{i t}$ é o montante dos investimentos estrangeiros diretos do país $i$ no período t, série do World Development Indicators;

$K G_{i t}$ é o gasto do governo como proporção do PIB do país $i$ no período $t$, série da World Penn Tables 6.2;

$\mathrm{I}_{\mathrm{it}}$ é a taxa de juros reais do país $i$ no período t, série do World Development Indicators;

$\mathrm{PIB}_{\mathrm{it}}$ é o PIB per capita em dólares do país $i$ no período $t$, série do $W$ orld Development Indicators;

$\psi_{\mathrm{t}}$ são variáveis dummy de ano, para um período de cada cinco anos, $\varepsilon_{\mathrm{it}}$ é o resíduo estocástico.
A Tabela 2 apresenta os resultados estimados para seis especificações (I)-(VII) de painéis dinâmicos para a poupança doméstica como proporção do PIB. Os testes Arellano-Bond rejeitam a autocorrelação nos resíduos de segunda ordem, apropriadamente. Os testes J de Hansen e o teste Hansen-Difference rejeitam a hipótese de sobre-identificação inválida para os instrumentos em nível e em diferença: os instrumentos para as variáveis endógenas são, a princípio, válidos. Os resultados das estimações, em todas as especificações, apontam uma robusta e significativa relação positiva entre o índice de desvalorização relativa da taxa de câmbio real calculada anteriormente e a poupança doméstica/PIB, em contraste com os resultados de Montiel e Sérven (2008). Entre outros motivos, a diferença nos resultados dos papers pode estar na amostra selecionada, que aqui se limitam a países de renda média, ou à especificação diversa que este trabalho dá à taxa de câmbio real, com seus efeitos obtidos a partir de um índice de desvalorização calculado como o desvio para baixo (depreciação) da taxa de câmbio de equilíbrio de longo, em vez de lidar com a taxa de câmbio real em nível.

Os resultados indicam também que a desvalorização relativa da taxa de 
Tabela 2_System GMM para poupança doméstica/PIB

\begin{tabular}{|c|c|c|c|c|c|c|c|}
\hline System GMM & $\mathbf{I}$ & II & III & IV & V & VI & VII \\
\hline \multirow[t]{2}{*}{ Poupança interna_1 } & 0,887 & 0,899 & 0,884 & 0,907 & 0,873 & 0,910 & 0.880 \\
\hline & $(0,005)^{*}$ & $(0,008) *$ & $(0,012)^{*}$ & $(0,011)^{*}$ & $(0,023)^{*}$ & $(0,020)^{*}$ & $(0.018)$ \\
\hline \multirow[t]{2}{*}{ Conta-corrente } & 0,187 & 0,174 & 0,157 & 0,181 & 0,158 & 0,175 & 0.178 \\
\hline & $(0,005)^{*}$ & $(0,011)^{*}$ & $(0,012)^{*}$ & $(0,011)^{*}$ & $(0,025)^{*}$ & $(0,020)^{*}$ & $(0.011)^{*}$ \\
\hline \multirow[t]{2}{*}{ Depreciação real do câmbio } & - & 0,566 & 1,017 & 1,109 & 0,639 & 0,955 & 1.123 \\
\hline & - & $(0,298)^{*}$ & $(0,290)^{*}$ & $(0,255)^{*}$ & $(0,356)^{*}$ & $(0,525)^{*}$ & $(0.460)^{*}$ \\
\hline \multirow[t]{2}{*}{ Crescimento PIB per capita } & - & - & 0,277 & 0,234 & 0,252 & 0,228 & 0.234 \\
\hline & - & - & $(0,012)^{*}$ & $(0,014)^{*}$ & $(0,021)^{*}$ & $(0,033)^{*}$ & $(0.025)^{*}$ \\
\hline \multirow[t]{2}{*}{ Abertura comercial } & - & - & $-0,005$ & $-0,006$ & $-0,011$ & $-0,014$ & -0.031 \\
\hline & - & - & $-(0,003)$ & $-(0,005)$ & $-0,005$ & $(0,008)^{*}$ & $(0.010)^{*}$ \\
\hline \multirow[t]{2}{*}{ Investimentos estrangeiros diretos } & - & - & - & 0,141 & 0,179 & 0,103 & 0.111 \\
\hline & - & - & - & $(0,024)^{*}$ & $(0,044)^{*}$ & $(0,043)^{*}$ & $(0.028)^{*}$ \\
\hline \multirow[t]{2}{*}{ Gastos do governo/PIB } & - & - & - & - & $-0,063$ & $-0,048$ & -0.012 \\
\hline & - & - & - & - & $(0,035)^{*}$ & $(0,055)$ & $(0.056)$ \\
\hline \multirow[t]{2}{*}{ Taxa de juros reais } & - & - & - & - & - & $-0,035$ & -0.037 \\
\hline & - & - & - & - & - & $(0,009)^{*}$ & $(0.007)^{*}$ \\
\hline \multirow[t]{2}{*}{ PIB per capita } & - & - & - & - & - & - & 2.1E-04 \\
\hline & - & - & - & - & - & - & $(1.7 \mathrm{E}-04)$ \\
\hline Year dummies & - & - & - & - & $\mathrm{Sim}$ & $\mathrm{Sim}$ & Sim \\
\hline \multirow[t]{2}{*}{ Constante } & 2,609 & 2,402 & 2,508 & 2,093 & 4,137 & 3,709 & 3.641 \\
\hline & $(0,084)^{*}$ & $(0,179)^{*}$ & $(0,367)^{*}$ & $(0,468)^{*}$ & $(0,946)^{*}$ & $-1,499$ & $(2.135)^{*}$ \\
\hline AR teste $\mathrm{AR}(1)$ & 0,000 & 0,000 & 0,000 & 0,000 & 0,000 & 0,000 & 0,000 \\
\hline AR teste $\mathrm{AR}(2)$ & 0,431 & 0,457 & 0,369 & 0,78 & 0,772 & 0,841 & 0,821 \\
\hline Teste J de Hansen Chi(2) & 73,35 & 71,68 & 64,45 & 68,06 & 61,29 & 60,72 & 62,72 \\
\hline Hansen Difference Chi(2) & 67,96 & 70,98 & 62,28 & 64,72 & 58,47 & 53.22 & 55,33 \\
\hline Número de observações & 1218 & 1143 & 1134 & 1075 & 1075 & 891 & 891 \\
\hline Número de países $\ldots . \ldots \ldots \ldots . . . \ldots$ & 76 & 76 & 76 & $\begin{array}{c}72 \\
\ldots \ldots\end{array}$ & 72 & 65 & 65 \\
\hline \multicolumn{8}{|l|}{$(*)$ significante a $10 \%$ de significância. } \\
\hline \multicolumn{8}{|l|}{ Fonte: Resultados da pesquisa. } \\
\hline \multicolumn{8}{|c|}{$\begin{array}{l}\text { Obs.:(1) Em todas as especificações, "Conta-Corrente/PIB" e "Depreciação Real do Câmbio" } \\
\text { são variáveis tratadas como endógenas e instrumentadas com o System-GMM. }\end{array}$} \\
\hline
\end{tabular}


câmbio que opera no crescimento pode fazê-lo por meio de seus efeitos benéficos na taxa de poupança interna. A variável de nível de produto per capita é incluída na especificação (VII) por três motivos: além de compor a especificação da poupança doméstica, a variável serve como a de controle daqueles países de renda média na posição superior da distribuição (bigh middle income countries) ante os países na posição inferior (low middle income countries).

O terceiro motivo é avaliar a hipótese levantada em Montiel e Sérven (2008) de que os efeitos do câmbio real sobre as taxas de poupança doméstica desaparecem, uma vez que se controle a renda em nível dos países em questão (entre outros determinantes da poupança). Os resultados mostram que a inclusão da variável em nível do produto não afeta o resultado geral das especificações na direção de uma robusta relação positiva entre o câmbio real e as taxas de poupança doméstica. Mais ainda, os resultados das especificações (II-VII) mostram importância para o crescimento do produto per capita na relação com a poupança doméstica, e não para o produto per capita em nível (que apresenta na especificação (VII) magnitude próxima de zero e não é estatisticamente significante). Tal- vez o fato de estar sendo utilizado neste trabalho um índice de desvalorização do câmbio, e não a taxa de câmbio real em nível, seja crucial para definir empiricamente os efeitos do câmbio sobre a acumulação do capital.

É interessante notar que, se por um lado o modelo econométrico aponta que a poupança externa efetivamente tem um grau de displacement na poupança interna, os coeficientes para a variável que descreve os investimentos estrangeiros diretos são positivos e significantes. Parece haver evidente diferença de efeitos sobre a poupança doméstica de fluxos que vem de déficits comerciais poupança externa ${ }^{2}$ - e daqueles fluxos que advêm como investimento direto. Talvez o investimento direto tenha externalidades de transbordamento sobre o investimento interno e, assim, sobre a expansão da poupança doméstica.

A abertura comercial, medida como a soma das exportações mais importações sobre o PIB, aparece nas especificações (III)-(VII). O sinal é negativo, porém não significante a $10 \%$. Os gastos do governo como parcela do PIB aparecem com correlação negativa e significante no que diz respeito à poupança interna como proporção ao PIB nas especificações (V-VII), e negativo e não
O fluxo de capitais estrangeiros é captado como proxy pelos resultados da conta-corrente. Uma série mais ampla, nesse sentido, seriam os passivos estrangeiros líquidos. 
significante nas especificações (VII-VIII). Esses resultados podem sinalizar que a poupança do governo é favorável à poupança interna, embora uma relação com a poupança privada, em vez de utilizarse a poupança doméstica como foi feito neste trabalho, esclarecesse melhor a possibilidade de crowding-in para os países emergentes. As taxas reais de juros aparecem com sinais negativos e significantes, nas especificações (VI) e (VII), como é comum na literatura do tema.

\section{4_Algumas conclusões}

O trabalho apresentou perspectivas teóricas e empíricas que exploram o canal macroeconômico dos efeitos do câmbio sobre a poupança doméstica. Os argumentos apresentados nas seções anteriores procuraram discutir os impactos do nível do câmbio real nos salários reais, nas taxas de lucro, no investimento agregado, nas poupanças externa e interna. Dentro do modelo explorado, em casos de sobrevalorização excessiva, a redução de margens de lucro nos setores de produção de bens comercializáveis significará queda importante na poupança agregada doméstica.

Alguns autores têm argumentado que o modelo asiático não seria implementável no Brasil ou na América Lati- na em razão do baixo nível de poupança privada. Tratando a conta-corrente como resíduo, argumentam que a baixa propensão individual a consumir dos asiáticos seria responsável pelos altos níveis de poupança doméstica e superávits em conta-corrente. Sem entrar em explicações "culturalistas", o modelo acima exposto endogeniza o consumo agregado como função do salário real, que, por sua vez, depende do câmbio real. Assim, o segredo para o alto nível de poupança dos asiáticos estaria, segundo o modelo, nos reduzidos salários reais, dado um nível de produtividade.

Vale notar que toda essa discussão é feita com base em determinados níveis de produtividade. A elevação do salário real sem contrapartida de aumentos de produtividade é problemática, uma vez que acaba por colocar a economia numa trajetória insustentável que termina numa crise de balanço de pagamentos. Por outro lado, numa situação de câmbio competitivo, há aumento de lucratividade dos investimentos e exportações que tende a elevar o nível de produtividade da economia no longo prazo, permitindo majoração de salários reais de forma equilibrada.

A análise econométrica do trabalho indica que a desvalorização relativa 
da taxa de câmbio que opera no crescimento pode também fazê-lo por meio de seus efeitos benéficos na taxa de poupança doméstica. Os resultados das estimações, em todas as especificações, apontam robusta e significativa relação positiva entre o índice de desvalorização relativa da taxa de câmbio real calculada anteriormente e a poupança doméstica/PIB. Além disso, é interessante notar que, se por um lado o modelo econométrico mostra que a poupança externa efetivamente tem um grau de displacement na poupança interna, os coeficientes para a variável que descreve os investimentos estrangeiros diretos são positivos e significantes. 


\section{Referências bibliográficas}

ARELLANO, M.; BOND, B. Some test specification for Panel Data: Monte Carlo evidence and an application to employment equations. Review of Economic Studies, 1991.

ARELLANO, M.; BOVER, O. Another look at the instrumentalvariable estimation of errorcomponents models, Journal of Econometrics, v. 68, 1995.

BALTAGI, B. Econometric analisys of Panel Data. John Wiley \& Sons, 2005.

BLUNDEL, R.; BOND, A. Estimation in dynamic Panel Data Models: improving on the performance of The Standard GMM Estimators. The Institute for Fiscal Studies, 2000.

BHADURI, A.; MARGLIN, S. A. Unemployment and the real wages: The economic basis for contesting political ideologies. Cambridge Journal of Economics, v. 14, Dec. 1990.

BRESSER-PEREIRA, L. C. Exchange rate, fix, float or manage it? Preface to Mathias Vernengo (Ed.). Financial integration or dollarization: no panacea. Cheltenham: Edward Elgar, 2006.
BRESSER-PEREIRA, L. C.; NAKANO, Y. Crescimento com poupança externa? Revista de Economia Política, v. 23, n. 2, abr./jun. 2003.

EICHENGREEN, B. The real exchange rate and economic growth, Word Bank, Working Paper n. 8,2008 .

EDWARDS, S. Why are saving rates so different across countries? An international comparative analysis. NBER Working Paper, n. W5097, 1995.

FRENKEL, R.; TAYLOR, L. Real exchange rate, monetary policy and employment. Desa Working paper n. 19, United Nations,

New York, 2006.

HESTON, A.; SUMMERS,

R.; ATINA, B. Penn World

Table Version 6.2, Center for International Comparisons of Production, Income and Prices at the University of Pennsylvania, 2006.

MONTIEL, P.; SÉRVEN, L. Real exchange rate, savings and growth: Is there a link? Policy research working paper. The World Bank, Washington, 2008.
REINHART, C.; TALVI,

E. Capital flows and savings in Latin America and Asia: a reinterpretation. Journal of Development Economics, v. 57, 1998.

RODRIK, D. Real exchange rate and economic growth: Theory and Evidence, John F. Kennedy School of Government, Harvard University, Draft, July 2008.

WILLIAMSON, J. Exchange rate economics. Working Paper Series,

Peterson Institute for International Economics, Washington, 2008.

WINDMEIJER, F. A finite sample correction for the variance of linear two-step GMM estimator. Journal of Econometrics, v. 126, n. 1, 2005.

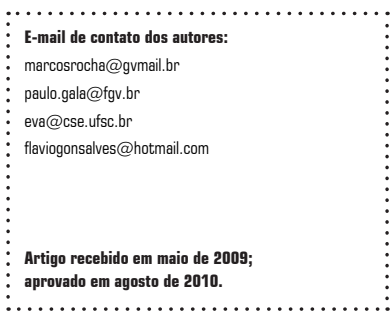

